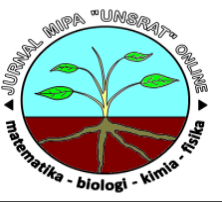

\title{
Biodiversitas Burung pada Beberapa Tipe Habitat di Kampus Universitas Sam Ratulangi
}

\author{
Ratih Dwi Rumanasaria, Saroyoa*,Deidy Y. Katilia* \\ aJurusan Biologi, FMIPA, Unsrat, Manado
}

KATA KUNCI

Biodiversitas, Burung.

\begin{abstract}
A B S T R A K
Burung merupakan salah satu hewan yang memiliki kaitan erat dengan kehidupan manusia sejak dahulu kala. Fungsi ekologis burung yaitu sebagai penyebar biji dan penyerbuk alami. Burung juga dimanfaatkan manusia sebagai bahan makanan serta sebagai hewan peliharaan, bahkan burung juga turut berperan dalam berbagai budaya masyarakat. Penelitian ini bertujuan untuk menentukan tingkat biodiversitas burung di daerah Kampus Universitas Sam Ratulangi Manado berdasarkan nilai indeks Shannon-Wiener. Penelitian ini menggunakan metode purposive sampling yang dilaksanakan pada bulan Desember 2016-Maret 2017. Berdasarkan hasil penelitian terdapat sembilan jenis yang ditemukan yaitu, Butorides striatus, Collocalia esculenta, Passer montanus, Pycnonotus aurigaster, Geopelia striata, Gallirallus torquatus, Hirundo tahitica, Nectarinia jugularis, dan Halcyon chloris. Burung yang paling banyak ditemukan adalah Collocalia esculenta dan yang paling sedikit adalah Butorides striatus. Indeks keanekaragaman dari burung yang diamati termasuk dalam kategori sedang melimpah yaitu, 1,638.
\end{abstract}

K E Y W O R D S

Biodiversity, Bird.

\begin{abstract}
A B S T R A C T
Bird is one of the animals that has a closed relationship with human life since a long time ago. The ecological functions of birds are as natural seed dispersers and pollinators. Birds are also used by humans as food material and as a pet, even birds also play a role in various cultures of society. This study aims to determine the level of bird biodiversity in the area of University of Sam Ratulangi Manado based on Shannon-Wiener index value. This study used purposive sampling method conducted in December 2016-March 2017. Based on the results of the study there were nine species found, namely Butorides striatus, Collocalia esculenta, Passer montanus, Pycnonotus aurigaster, Geopelia striata, Gallirallus torquatus, Hirundo tahitica, Nectarinia jugularis, and Halcyon chloris. The most bird that commonly found is Collocalia esculenta and the fewest is Butorides striatus. The index diversity value of birds is 1,638 that belongs to abundant category.
\end{abstract}

TERSEDIA ONLINE

1 Februari 2017

\section{Pendahuluan}

Sulawesi memiliki jenis-jenis satwa endemik karena terletak di Kawasan Wallacea. Kawasan ini merupakan wilayah transisi yang terletak di antara Benua Asia dan Australia (Lee et al., 2001). Pulau ini memiliki beragam habitat untuk penyebaran jenis-jenis satwa di atas, antara lain burung (Coates and Bishop, 2000). Burung merupakan salah satu hewan yang memiliki kaitan erat dengan kehidupan manusia sejak dahulu kala. Fungsi ekologis burung yaitu sebagai penyebar biji dan penyerbuk alami.
Burung juga dimanfaatkan manusia sebagai bahan makanan serta sebagai hewan peliharaan, bahkan burung juga turut berperan dalam berbagai budaya masyarakat. Biodiversitas burung dapat dijadikan indikator baik buruknya kualitas habitat karena memiliki karakteristik penting, antara lain dapat hidup pada berbagai habitat di seluruh dunia, peka terhadap perubahan lingkungan, dan penyebarannya sudah cukup diketahui (Kinnaird, 1997). Burung hidup hampir di seluruh tipe habitat dan pada berbagai ketinggian tempat. Tipe habitat burung sangat berhubungan dengan kehidupan dan

*Corresponding author: Jurusan Biologi FMIPA UNSRAT, Jl. Kampus Unsrat, Manado, Indonesia 95115; Email address: ratihdwirumanasari@gmail.com Published by FMIPA UNSRAT (2017) 
aktivitas hariannya seperti tempat untuk beristirahat, bertengger, aktivitas kawin, aktivitas makan, berlindung, dan bersarang (Syafrudin, 2011).

Salah satu lokasi yang memiliki tipe-tipe habitat untuk burung ialah Kampus Universitas Sam Ratulangi Manado. Di daerah Kampus Universitas Sam Ratulangi Manado terdapat beberapa tipe habitat burung yaitu tanah berhutan (wodland), perairan (rawa/kolam), dan semak.

Kampus sebagai pusat aktivitas pendidikan dan pembangunan yang dilaksanakan di kampus yang semakin pesat menyebabkan habitat burung semakin berkurang, sehingga tidak ada tempat bagi burung untuk berkembang biak dengan baik. Walaupun demikian, daerah Universitas Sam Ratulangi Manado masih memiliki tipe-tipe habitat seperti yang disebutkan di atas yang dapat mendukung kehidupan burung.

Penelitian ini bertujuan menentukan tingkat biodiversitas burung pada beberapa tipe habitat di daerah Kampus Universitas Sam Ratulangi Manado berdasarkan nilai indeks Shannon-Wiener.

\section{Material dan Metode}

Penelitian ini dilaksanakan di daerah Kampus Universitas Sam Ratulangi Manado, pada bulan Desember 2016 - Maret 2017. Peralatan yang digunakan adalah binokuler, buku identifikasi, buku lapangan, kamera, alat-tulis menulis, dan GPS.

Prosedur penelitian meliputi penentuan habitat, pengambilan data, dan analisis data. Dalam penelitian ini digunakan tiga tipe habitat, yaitu tanah berhutan (analog hutan sekunder), semak, dan rawa. Pengambilan data jenis burung tiap plot pada setiap habitat dilaksanakan selama 5 hari. Pengamatan dilaksanakan mulai pukul 06.00-17.00 WITA. Informasi yang dikumpulkan meliputi waktu, jenis burung, jumlah burung, dan aktifitas burung yang dilakukan. Identifikasi jenis burung menggunakan buku Panduan Lapangan BurungBurung di Kawasan Wallacea (Coates and Bishop, 2000) dan Burung-Burung di Sulawesi (Holmes and Phillips, 1999). Burung diindentifikasi berdasarkan ciri-ciri morfologi, yaitu bentuk paruh dan warna bulu. Selanjutnya dibuat sketsa/gambar burung atau difoto dengan menggunakan kamera.

Rumus yang digunakan dalam menentukan tingkat biodiversitas burung ialah:

1. Kelimpahan Burung

Kelimpahan merupakan jumlah individu burung yang ditemukan selama pengamatan. Indeks kelimpahan memberikan gambaran suatu komposisi jenis dalam komunitas. Untuk menghitung kelimpahan tiap jenis digunakan rumus menurut Fachrul (2007) sebagai berikut:

$$
\begin{aligned}
& \mathrm{Pi}=(\Sigma \text { burung spesies } \mathrm{i}) /(\Sigma \text { total burung }) \\
& \quad \text { Dengan: } \\
& \mathrm{Pi}=\text { nilai kelimpahan burung }
\end{aligned}
$$

2. Biodiversitas Jenis Burung
Menurut Fachrul (2007) nilai keanekaragaman diperoleh dengan menggunakan indeks keanekaragaman Shannon-Wiener dengan menggunakan rumus:

$$
\begin{aligned}
& \quad \mathrm{H}^{\prime}=-\Sigma \text { pi Inilo } \\
& \text { Dengan: } \\
& \mathrm{H}^{\prime}=\text { indeks biodiversitas jenis } \\
& \mathrm{Pi}=\text { nilai kelimpahan burung. }
\end{aligned}
$$

\section{Hasil dan Pembahasan}

1. Kondisi Lingkungan Lokasi Penelitian

Lokasi penelitian di Kampus Universitas Sam Ratulangi memiliki beberapa tipe habitat yang menunjang kehidupan burung seperti tanah berhutan, semak, dan danau/rawa. Berbagai habitat ini berfungsi sebagai tempat berlindung dan bersarang, mencari makan, dan bereproduksi bagi jenis-jenis burung yang ada. Berikut deskripsi dari tipe-tipe habitat yang dijadikan lokasi pengamatan.

\subsection{Habitat Tanah berhutan FMIPA}

Pada habitat tanah berhutan FMIPA dengan kondisi lingkungan yang banyak ditanami pohon memungkinkan bagi beberapa jenis burung untuk hidup di tempat ini. Habitat ini merupakan daerah bekas rawa. Burung yang hidup pada habitat ini seperti: Colocalia esculenta, Pycnonotus aurigaster, Geopelia striata, Passer montanus, dan Nectarinia jugularis.

\subsection{Habitat Tanah berhutan Fakultas Kedokteran}

Habitat ini memiliki karakteristik yang mirip dengan lokasi tanah berhutan FMIPA dimana kondisi lingkungan banyak ditumbuhi pohon berkayu. Jenis-jenis burung yang ditemukan di sini juga sama dengan jenis-jenis yang ditemukan di habitat tanah berhutan FMIPA.

\subsection{Habitat Semak FKM}

Habitat ini merupakan hutan sekunder yang menyediakan tempat hidup yang baik bagi beberapa jenis burung. Pada habitat ini ditemukan jenis Passer montanus, Collocalia esculenta, Pycnonotus aurigaster, Geopelia striata, Gallirallus torquatus, dan Hirundo tahitica.

\subsection{Habitat Rawa samping BNI}

Pada habitat ini berupa rawa yang terdiri dari beberapa jenis tumbuhan yang hidup di sekitar seperti: Bougainvillea, dan Swietenia mahagoni. Pada daerah Kampus Universitas Sam Ratulangi dengan kodisi lingkungan yang banyak ditanami pohon memungkinkan bagi beberapa jenis burung untuk hidup. Burung Halcyon cloris mencari makan di sekitar rawa samping BNI yang banyak dihidupi oleh ikan-ikan kecil.

\subsection{Habitat Rawa FMIPA}

Di Kampus Universitas Sam Ratulangi terdapat habitat yang merupakan lahan yang dimodifikasi menjadi rawa ini banyak ditumbuhi Eichhornia crassipes, Nymphaea sp., Lilium sp., dan Bougainvillea. Pada habitat ini masih menyediakan 
sedikit tempat hidup bagi jenis burung Butorides striatus.

2. Indeks Keanekaragaman Burung di Kampus Universitas Sam Ratulangi

Berdasarkan hasil pengamatan jumlah jenis dan jumlah individu, serta perhitungan dengan menggunakan indeks Shannon-Wiener, diperoleh indeks keanekaragaman burung di Kampus Universitas Sam Ratulangi dengan nilai 1,638 termasuk kategori sedang melimpah. Burung yang paling banyak ditemukan adalah jenis Collocalia esculenta dan yang paling sedikit adalah Butorides striatus.

Biodiversitas burung pada tiap habitat berbedabeda, hal tersebut dapat dipengaruhi oleh perbedaan tipe habitat di tiap lokasi. Semakin tinggi keanekaragaman habitat akan mendukung tingginya keanekaragaman jenis burung di wilayah tersebut, karena habitat bagi satwa liar secara umum berfungsi sebagai tempat untuk mencari makan, minum, istirahat, dan berkembang biak (Alikodra, 1990). Indeks keanekaragaman akan tinggi apabila pada suatu habitat dapat mendukung berbagai aktivitas dan mampu memberikan tempat yang nyaman untuk berlindung dan berkembang biak (Yayuk, 2013). Selain itu apabila habitat tidak lagi memenuhi kebutuhan hidup, maka burung tersebut akan berpindah ke tempat yang lebih nyaman

Table 1. Indeks Keanekaragaman Burung di tiap lokasi penelitian

\begin{tabular}{|l|l|c|l|}
\hline No & \multicolumn{1}{|c|}{ Lokasi Penelitian } & Jumlah spesies & $\mathrm{H}^{\prime}$ \\
\hline 1 & Tanah berhutan FMIPA & 5 & 1,164 \\
\hline 2 & Tanah berhutan Kedokterran & 5 & 1,322 \\
\hline 3 & Semak FKM & 6 & 1,613 \\
\hline 4 & Rawa samping BNI & 6 & 1,390 \\
\hline 5 & Rawa FMIPA & 4 & 1,154 \\
\hline
\end{tabular}

Table 2. Indeks Keanekaragaman Burung di Kampus Universitas Sam Ratulangi

\begin{tabular}{|l|l|l|l|l|l|l|l|}
\hline Jenis Burung & Jumlah & $\begin{array}{l}\text { Densitas } \\
\text { (Ekor/ha) }\end{array}$ & ni/N & Pi & Ln Pi & Pi Ln Pi & $H^{\prime}$ \\
\hline B. striatus & 25 & 19.328 & 0.0047 & 0.007 & -5.018 & -0.033 & \\
\hline C. esculenta & 1683 & 1301.1 & 0.3155 & 0.446 & -0.808 & -0.36 \\
\hline P. montanus & 1584 & 1224.6 & 0.2969 & 0.419 & -0.869 & -0.364 \\
\hline P. aurigaster & 1438 & 1111.7 & 0.2695 & 0.381 & -0.965 & -0.368 \\
\hline G. striata & 235 & 181.68 & 0.044 & 0.062 & -2.777 & -0.173 & \multirow{2}{*}{1,638} \\
\hline G. torquatus & 213 & 164.67 & 0.0399 & 0.056 & -2.875 & -0.162 & \\
\hline H. tahitica & 46 & 35.563 & 0.0086 & 0.012 & -4.408 & -0.054 \\
\hline N. jugularis & 58 & 44.84 & 0.0109 & 0.015 & -4.176 & -0.064 \\
\hline H. chloris & 53 & 40.975 & 0.0099 & 0.014 & -4.266 & -0.06 \\
\hline Total & 5335 & 4124.5 & 0.7078 & 1.413 & -26.16 & -1.638 & \\
\hline
\end{tabular}

Ket: $n i=$ jumlah individu suatu jenis, $\mathrm{pi}=$ jumlah total individu seluruh jenis, $\mathrm{H}^{\prime}$ = indeks keanekaragaman

Habitat semak FKM memiliki indeks keanekaragaman tertinggi sebesar 1,613, di habitat ini dijumpai jenis burung yang banyak dibandingkan dengan habitat yang lain sebanyak enam jenis. Tingginya keanekaragaman di habitat ini disebabkan karena area ini merupakan area yang masih alami yang ditumbuhi beberapa jenis pohonpohon, semak hingga rumput-rumput, dan jauh dari gangguan aktivitas manusia (Widodo, 2009). Habitat rawa FMIPA memiliki indeks keanekaragaman terendah sebesar 1,155, di habitat ini hanya ditemukan empat jenis burung. Hal ini dikarenakan aktivitas manusia dan pembangunan yang ada di sekitar habitat menyebabkan burung yang ada di habitat ini semakin berkurang atau pindah ke tempat yang lain.

Menurut Howes et al. (2003), kehadiran suatu jenis burung tertentu umumnya disesuaikan oleh kesukaanya terhadap habitat tertentu. Faktor yang menyebabkan tingkat kehadiran tersebut disebabkan oleh kondisi habitat yang baik. Habitat yang baik akan lebih sering dimanfaatkan oleh jenis burung sebagai habitat utamanya karena pada habitat tersebut jenis-jenis burung mendapatkan 
sumber makanannya dan juga sebagai tempat berlindung ketika ada pemangsa atau sebagai tempat berlindung dari cuaca yang buruk. Selain itu jenis burung yang banyak ditemukan di tiap lokasi merupakan jenis burung yang mempunyai daya adaptasi baik terhadap aktivitas manusia.

Berdasarkan hasil pengamatan terdapat tiga jenis burung yang ditemukan di semua habitat yaitu Colocalia esculenta, Pycnonotus aurigaster, dan Passer montanus. Sementara jenis burung yang hanya ditemukan di beberapa habitat yaitu Butorides striatus, Hirundo tahitica, Nectarinia jugularis, Geopelia striata, Halcyon cloris, dan Gallirallus torquatus. Jenis burung yang ditemukan di tiap habitat mempunyai arti bahwa habitat tersebut sesuai untuk kehidupan jenis burung yang ada, sedangkan jenis burung yang hanya ditemukan di beberapa habitat mempunyai arti bahwa habitat tersebut tidak sesuai bagi kebutuhan tempat untuk kehidupan burung. Perbedaan jenis burung disebabkan oleh perbedaan jenis tumbuhan, tingkat kenyamanan, dan aktivitas manusia yang ada (Jarulis, 2005).

Burung yang paling sering dijumpai di Kampus Universitas Sam Ratulangi adalah Colocalia esculenta. Burung ini dapat ditemukan di tiap habitat. Colocalia esculenta dapat bertahan hidup karena habitat dan makanan yang ada di daerah ini mendukung kelangsungan hidupnya dan memiliki kebiasaan terbang dengan bebas di semua tipe habitat. Passer montanus merupakan jenis burung yang paling banyak ditemukan di tiap habitat setelah Colocalia esculenta. Burung ini mampu berasosiasi dekat dengan manusia, hidup berkelompok dan mencari makan di tanah (MacKinnon et al., 2010).

Burung yang paling sedikit ditemukan adalah Butorides striatus, Hirundo tahitica, Nectarinia jugularis, Geopelia striata, Halcyon cloris, dan Gallirallus torquatus. Burung-burung tersebut hanya ditemukan di beberapa habitat selama pengamatan hal ini dikarenakan burung tersebut datang untuk beristirahat dan mencari makan kemudian terbang.

\section{Kesimpulan}

Berdasarkan penelitian yang telah dilakukan terdapat sembilan jenis burung yang ditemukan adalah: Butorides striatus, Collocalia esculenta, Passer montanus, Pycnonotus aurigaster, Geopelia striata, Gallirallus torquatus, Hirundo tahitica, Nectarinia jugularis, dan Halcyon chloris. Indeks keanekaragaman burung termasuk dalam kategori sedang melimpah.

\section{Daftar Pustaka}

Alikodra, H. S. 1980. Dasar-Dasar Pembinaan Margasatwa. Fakultas Kehutanan Institut Pertanian Bogor, Bogor.

Coates, B. J and D, Bishop. 2000. Panduan Lapangan Burung- Burung di Kawasan Wallaceae (Sulawesi, Maluku dan Nusa Tenggara, Indonesia). Penerbit Birdlife, Bogor.

Fachrul, F. M. 2007. Metode Sampling Bioekologi. Bumi Askara, Jakarta.

Holmes, D and K, Phillips. 1999. Burung-Burung di Sulawesi. Puslitbang Biologi-LPI, Jakarta.

Howes, J., D, Bakewell and Y. R, Noor. 2003. Panduan Studi Burung Pantai. Wetlands Internasional, Bogor.

Jarulis. 2005. Fauna Burung di Taman Kota dan Jalur Hijau Kota Padang. Jurnal Gradien. 1(2): 98-104.

Kinnaird, F. Margareth, 1997. Sulawesi Utara: Sebuah Panduan Sejarah Alam. Yayasan Pengembangan Wallace, Indonesia.

Lee, R. J., J, Riley., R, Merrill and R. P, Manoppo. 2001. Keanekaragaman Hayati dan Konservasi di Sulawesi Bagian Utara. WCS IP Sulawesi, Departemen Kehutanan (PKA) dan natural Resources management Progam, Manado.

Mackinnon, J., K, Philips and B. B, Van. 2010. Burung-burung di Sumatra, Jawa, Bali, dan Kalimantan. Bogor: Pustlitbang BiologiLIPI/Birdlife, Indonesia.

Syafrudin, D. 2011. Keanekaragaman Jenis Burung Pada Beberapa Tipe Habitat di Tambling Wildlife Nature Conservation (Twnc), Taman Nasional Bukit Barisan Selatan Lampung [skripsi]. Departemen Konservasi Sumber Daya Hutan dan Ekowisata Fakultas Kehutanan Institut Pertanian Bogor, Bogor.

Widodo, 2009. Komparasi Keragaman Jenis BurungBurung di Taman Nasional Baluran dan Alas Purwo pada Beberapa Tipe Habitat. Berk, Panel, Hayati. 14:113-124.

Yayuk, W., 2013. Keanekaragaman Jenis Burung Diural dalam Kawasan Cagar Alam Mandor Kabupaten Landak. 